\title{
NITRATO NO SOLO COM A APLICAÇÃO DE DEJETOS LÍQUIDOS DE SUÍNOS NO MILHO EM PLANTIO DIRETO(1)
}

\author{
Celso Aita ${ }^{(2)} \&$ Sandro José Giacomini ${ }^{(3)}$
}

\begin{abstract}
RESUMO
A aplicação de dejetos de animais ao solo, com destaque para aqueles gerados na suinocultura, é uma prática cada vez mais comum na Região Sul do Brasil. Todavia, em função da dose aplicada, esta prática poderá provocar perda de nutrientes, principalmente de $\mathrm{NO}_{3}{ }^{-}$, por lixiviação e escoamento superficial em direção aos cursos d'água, e à atmosfera pela emissão de óxidos de $\mathrm{N}$. O objetivo deste trabalho foi avaliar o acúmulo e o deslocamento de $\mathrm{NO}_{3}{ }^{-}$no solo após a aplicação de dejetos líquidos de suínos no milho em plantio direto. As doses de 0 , 40 e $80 \mathrm{~m}^{3} \mathrm{ha}^{-1}$ de dejetos líquidos de suínos foram aplicadas anualmente, durante três anos, sobre os resíduos culturais de aveia-preta e da vegetação espontânea de inverno, antecedendo a semeadura do milho. Foi avaliado o teor de $\mathrm{N}-\mathrm{NO}_{3}{ }^{-} \mathrm{em}$ diferentes camadas do solo, até a profundidade de $60 \mathrm{~cm}$, e em seis datas, desde a aplicação dos dejetos até o florescimento do milho. Com a aplicação dos dejetos, a quantidade de $\mathrm{N}^{-\mathrm{NO}_{3}}{ }^{-}$aumentou rapidamente na camada superficial do solo, evidenciando a elevada taxa de nitrificação do $\mathrm{N}$ amoniacal que eles contêm. $\mathrm{O} N$ $\mathrm{NO}_{3}{ }^{-}$produzido nas camadas superficiais do solo percolou rapidamente no perfil. $\mathrm{Na}$ dose de $80 \mathrm{~m}^{3} \mathrm{ha}^{-1}$ de dejetos, a quantidade de $\mathrm{N}^{-\mathrm{NO}_{3}}{ }^{-}$da camada $30-60 \mathrm{~cm}$ do solo aos 30 dias no primeiro ano, 29 dias no segundo e 36 dias no terceiro ano foi maior do que a média dos tratamentos sem dejetos em 9, 21 e $32 \mathrm{~kg} \mathrm{ha}^{-1}$ de $\mathrm{N}_{-\mathrm{NO}_{3}}^{-}$, respectivamente. Nos dois primeiros anos, a quantidade de $\mathrm{N}_{-} \mathrm{NO}_{3}{ }^{-}$no perfil do solo não diferiu com a aplicação dos dejetos sobre os resíduos culturais de aveia ou da vegetação espontânea, revelando o baixo potencial dos resíduos culturais da gramínea em promover a imobilização microbiana de N. A elevada taxa de nitrificação do $\mathrm{N}$ amoniacal dos dejetos e o rápido deslocamento do $\mathrm{N}-\mathrm{NO}_{3}{ }^{-}$no perfil no momento em que a demanda em $\mathrm{N}$ pelo milho ainda era pequena, indicam maior susceptibilidade de perdas de $\mathrm{N}-\mathrm{NO}_{3}{ }^{-}$por lixiviação com a aplicação dos dejetos, principalmente na dose de $80 \mathrm{~m}^{3} \mathrm{ha}^{-1}$, em que a quantidade média de $\mathrm{N}$ total aplicada nos três anos foi de $244 \mathrm{~kg} \mathrm{ha}^{-1} \mathrm{ano}^{-1}$.
\end{abstract}

Termos de indexação: lixiviação de nitrato, adubação orgânica, resíduos culturais.

\footnotetext{
(1) Recebido para publicação em agosto de 2007 e aprovado em julho de 2008.

(2) Professor Associado do Departamento de Solos, Universidade Federal de Santa Maria - UFSM. Av. Roraima 1000, CEP 971059000 Santa Maria (RS). Bolsista do CNPq. E-mail: celsoaita@gmail.com

${ }^{(3)}$ Professor Adjunto do Departamento de Solos, UFSM. E-mail: sjgiacomini@smail.ufsm.br
} 


\title{
SUMMARY: SOIL NITRATE AS AFFECTED BY PIG SLURRY APPLICATION UNDER NO-TILL CORN
}

\begin{abstract}
The application of animal manure to the soil, particularly those generated in pig farms, has become an increasingly common practice in southern Brazil. However, depending on the dose applied, there is a risk of nutrient losses, mainly nitrate $\left(\mathrm{NO}_{3}{ }^{-}\right)$, to the water courses through leaching and runoff, and to the atmosphere as $\mathrm{N}$-oxide emissions. The

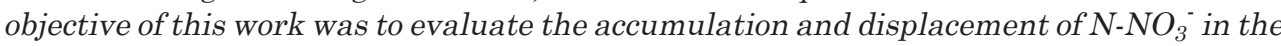
soil after pig slurry application in no-tillage corn. The doses of 0,40 and $80 \mathrm{~m}^{3} \mathrm{ha}^{-1}$ pig slurry were applied annually, for three years, on the mulch of cover crop of black oats and of winter spontaneous vegetation, preceding corn sowing. The $\mathrm{N}-\mathrm{NO}_{3}$ concentration was evaluated in different soil layers to a depth of $60 \mathrm{~cm}$ and on six dates, from the slurry application until corn tasseling. The amount of $\mathrm{N}-\mathrm{NO}_{3}{ }^{-}$increased quickly in the soil surface layer with the pig slurry application, evidencing the high nitrification rates of ammoniacal $\mathrm{N}$ in the slurry. $\mathrm{N}-\mathrm{NO}_{3}{ }^{-}$produced in the surface layers moved down quickly in the soil profile. At a dose of $80 \mathrm{~m}^{3} \mathrm{ha}^{-1}$ slurry the amounts of $\mathrm{N}-\mathrm{NO}_{3}{ }^{-}$in the $30-60 \mathrm{~cm}$ soil layer on the $30^{\text {th }}$ day of the first year, $29^{\text {th }}$ day in the second and $36^{\text {th }}$ day in the third year were

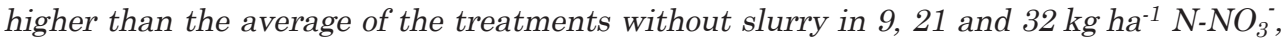
respectively. In the first two years the amount of soil $\mathrm{N}_{-} \mathrm{NO}_{3}{ }^{-}$in the surface layer did not differ with slurry application on mulch of oats or spontaneous vegetation, indicating the low potential of grass mulch in promoting microbial $N$ immobilization. The high rate of nitrification of ammoniacal $\mathrm{N}$ in the slurry and the fast displacement of $\mathrm{N}-\mathrm{NO}_{3}$ in the soil profile when the corn $\mathrm{N}$ demand was still small indicate a greater susceptibility of $\mathrm{N}-\mathrm{NO}_{3}{ }^{-}$ losses by leaching with slurry application, especially at a dose of $80 \mathrm{~m}^{3} \mathrm{ha}^{-1}$, where the average amount of total applied $N$ in the three years was $244 \mathrm{~kg} \mathrm{ha}^{-1}$ year-1.
\end{abstract}

Index terms: nitrate leaching, organic amendment, crop residues.

\section{INTRODUÇÃO}

Paralelamente à evolução da suinocultura, o sistema plantio direto (SPD) também tem experimentado forte expansão na última década, na região centro-sul do Brasil. O SPD constitui um sistema de manejo já consolidado, cuja premissa principal consiste na implantação das culturas sem o preparo do solo. Com isso, uma prática cada vez mais comum consiste na aplicação dos dejetos de suínos diretamente sobre os resíduos culturais de plantas de cobertura, com destaque para a aveia-preta, antecedendo a semeadura do milho. Nessa modalidade de uso dos dejetos, a dinâmica do $\mathrm{N}$ deve ser distinta daquela observada no sistema de preparo convencional do solo, com incorporação por meio de aração e gradagem. Além disso, o conhecimento já acumulado envolvendo o destino, no solo, do $\mathrm{N}$ aplicado com fertilizantes minerais poderá não se aplicar aos dejetos de animais, como enfatizam Flowers \& O'Callaghan (1983), já que estes apresentam, normalmente, $\mathrm{pH}$ elevado, teores elevados de $\mathrm{N}$ amoniacal, além de uma fração orgânica.

Os dejetos de suínos, constituídos por uma mistura de fezes e urina e outros materiais orgânicos, como restos de alimentos, além de uma quantidade variável de água, são normalmente manejados na forma líquida e armazenados em esterqueira anaeróbia, apresentando a maior parte do N na forma amoniacal quando aplicados no campo (Sommer \& Husted, 1995).
Conhecer a velocidade com que este $\mathrm{N}$ amoniacal é nitrificado no solo e o destino do $\mathrm{NO}_{3}{ }^{-}$produzido são aspectos fundamentais tanto do ponto de vista de aproveitamento do $\mathrm{N}$ dos dejetos pelas plantas como de poluição ambiental.

Trabalhando em campo e em clima temperado, Morvan et al. (1997) e Chantigny et al. (2001) constataram que o $\mathrm{N}$ amoniacal dos dejetos de suínos foi rapidamente nitrificado no solo. Em condições subtropicais, Aita et al. (2007), ao aplicarem $130 \mathrm{~kg} \mathrm{ha}^{-1}$ de $\mathrm{N}$ amoniacal com dejetos líquidos de suínos, verificaram que, 20 dias após a aplicação dos dejetos, praticamente todo o $\mathrm{N}$ amoniacal havia sido oxidado a nitrato. Com a rápida nitrificação do $\mathrm{N}$ amoniacal dos dejetos, o aparecimento do $\mathrm{N}-\mathrm{NO}_{3}{ }^{-}$no solo poderá ocorrer em uma velocidade superior à capacidade de sua absorção pelas plantas e pelos microrganismos. Nessa condição, poderá ocorrer perdas de $\mathrm{NO}_{3}{ }^{-}$por lixiviação, contaminando as águas de superfície e do lençol freático, e por desnitrificação, aumentando a emissão de $\mathrm{N}_{2} \mathrm{O}$ para a atmosfera, que é um gás de efeito estufa (Chantigny et al., 2004).

A adição ao solo, de materiais orgânicos com elevada relação $\mathrm{C} / \mathrm{N}$, como os resíduos culturais de cereais, poderá estimular a absorção de $\mathrm{N}-\mathrm{NO}_{3}{ }^{-}$pela biomassa microbiana, mantendo o $\mathrm{N}$ temporariamente na forma orgânica e diminuindo as perdas de $\mathrm{N}^{-} \mathrm{NO}_{3}{ }^{-}$ para o ambiente. Avaliando esse aspecto, Darwis (1993) constatou que, ao final de 348 dias, a adição ao solo de $8 \mathrm{Mg} \mathrm{ha}^{-1}$ de palha de trigo, com relação $\mathrm{C} / \mathrm{N}$ 
de 128, resultou em imobilização líquida de $12,2 \mathrm{~kg}$ de $\mathrm{N}$ para cada $\mathrm{Mg}$ de $\mathrm{C}$ adicionado ao solo com a palha. Com a adição conjunta de $60 \mathrm{~m}^{3} \mathrm{ha}^{-1}$ de dejetos líquidos de suínos (144 $\mathrm{kg} \mathrm{ha}^{-1}$ de $\mathrm{N}$ total), com 69,6 \% do $\mathrm{N}$ total na forma de $\mathrm{N}-\mathrm{NH}_{4}^{+}$, e $4 \mathrm{Mg}$ ha-1 de palha de cevada, Chantigny et al. (2001) verificaram que, na primeira semana, a quantidade de $\mathrm{N}$ mineral na camada de 0-20 cm do solo do tratamento com dejetos e palha foi significativamente menor do que aquela do tratamento apenas com dejetos, indicando a imobilização de $\mathrm{N}$ provocada pela adição da palha. É importante destacar que, nesses dois estudos, todos os materiais foram uniformemente incorporados ao solo.

Nas condições do centro-sul do Brasil, o efeito da adição dos dejetos de suínos juntamente com resíduos culturais de cereais, pobres em $\mathrm{N}$, visando estimular a imobilização de $\mathrm{NO}_{3}{ }^{-}$para diminuir suas perdas, não tem sido suficientemente avaliado. É importante quantificar a magnitude da imobilização, especialmente em plantio direto, em que tanto os resíduos culturais como os dejetos permanecem na superfície do solo. Outro aspecto que necessita ser mais bem avaliado refere-se ao efeito da quantidade e da fonte de $\mathrm{N}$ (orgânica ou mineral) sobre a variação temporal das quantidades de $\mathrm{N}-\mathrm{NO}_{3}{ }^{-}$no perfil do solo.

Este trabalho foi realizado em condições de campo, com o objetivo de avaliar o acúmulo e o deslocamento de $\mathrm{N}-\mathrm{NO}_{3}{ }^{-}$no solo após a aplicação anual, durante três anos, de dejetos líquidos de suínos no milho em plantio direto.

\section{MATERIAL E MÉTODOS}

O trabalho foi desenvolvido durante três anos agrícolas (1998/99, 1999/00 e 2000/01) na área experimental do Departamento de Solos da Universidade Federal de Santa Maria (RS) em um Argissolo Vermelho distrófico arênico (Hapludalf)
(Embrapa, 1999), com textura superficial francoarenosa no horizonte A e franco-argilosa no horizonte B. No início do experimento, o teor de argila do solo da camada $0-20 \mathrm{~cm}$ era de $150 \mathrm{~g} \mathrm{~kg}^{-1}$ e o teor de matéria orgânica de $16 \mathrm{~g} \mathrm{~kg}^{-1}$.

As avaliações foram realizadas em um experimento cujo objetivo era melhorar a eficiência dos dejetos de suínos como fertilizante para a cultura do milho em sistema plantio direto. O experimento foi realizado no delineamento experimental de blocos ao acaso, com parcelas subdivididas e três repetições. Em maio de 1998, foram demarcadas as parcelas principais (5 x $20 \mathrm{~m}$ ) onde foram implantados cinco sistemas de cultura (aveia/milho, aveia + ervilhaca/milho, ervilhaca/milho, pousio/milho, pousio/milho $+\mathrm{N}$ uréia). Em outubro de 1998, 1999 e 2000, as parcelas principais foram divididas em quatro subparcelas (5 x $5 \mathrm{~m})$, nas quais foram aplicadas doses de dejetos líquidos de suínos $\left(0,20,40\right.$ e $\left.80 \mathrm{~m}^{3} \mathrm{ha}^{-1}\right)$, imediatamente antes da semeadura da cultura do milho. As doses de dejetos foram aplicadas nas mesmas subparcelas em cada ano. Neste trabalho, nos três anos, as avaliações foram realizadas apenas nas subparcelas com as doses de dejetos de 0,40 e $80 \mathrm{~m}^{3} \mathrm{ha}^{-1}$ dos sistemas aveia/ milho e pousio/milho. No segundo e terceiro anos, avaliou-se também o sistema pousio/milho $+\mathrm{N}$ uréia, apenas na subparcela sem o uso de dejetos $\left(0 \mathrm{~m}^{3} \mathrm{ha}^{-1}\right)$.

No primeiro ano, os tratamentos foram aplicados sobre os resíduos culturais de aveia-preta e da vegetação espontânea de inverno da área (pousio); no segundo e terceiro ano, sobre os resíduos culturais de aveia/milho e vegetação espontânea/milho. No outono/ inverno do terceiro ano, os dejetos foram aplicados também nas parcelas com aveia, antecedendo a semeadura dessa, e nas parcelas em pousio. Por isso, no terceiro ano, os dejetos foram aplicados sobre quantidades maiores de resíduos culturais de aveia e da vegetação espontânea, em relação aos dois anos anteriores (Quadro 1). Em cada ano, e com no máximo duas semanas de antecedência ao início dos

Quadro 1. Matéria seca, nitrogênio e carbono nos resíduos culturais de aveia e da vegetação espontânea no momento do manejo, antecedendo a cultura do milho nos três anos de experimentação

\begin{tabular}{|c|c|c|c|c|c|c|c|c|c|c|c|}
\hline \multirow{2}{*}{ Sistema $^{(1)}$} & \multirow{2}{*}{$\begin{array}{c}\text { Fonte de } \mathrm{N} \\
\text { no milho }\end{array}$} & \multirow{2}{*}{ Dose } & \multicolumn{3}{|c|}{ Matéria seca } & \multicolumn{3}{|c|}{ Carbono } & \multicolumn{3}{|c|}{ Nitrogênio } \\
\hline & & & 98/99 & $99 / 00$ & $00 / 01$ & 98/99 & $99 / 00$ & $00 / 01$ & 98/99 & $99 / 00$ & $00 / 01$ \\
\hline & & & & 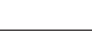 & $-\mathrm{Mg}$ & $a^{-1}$ & 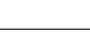 & $\underline{-}$ & 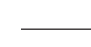 & $\mathrm{kg} \mathrm{ha}^{-1}$ & $\underline{-}$ \\
\hline \multirow[t]{3}{*}{ Aveia/milho } & Dejetos $\left(\mathrm{m}^{3} \mathrm{ha}^{-1}\right)$ & 0 & 4,60 & 3,10 & 3,27 & 1,93 & 1,29 & 1,35 & 43,2 & 31,7 & 39,8 \\
\hline & & 40 & 4,60 & 3,75 & 5,96 & 1,98 & 1,58 & 2,56 & 43,2 & 35,9 & 66,9 \\
\hline & & 80 & 4,60 & 3,90 & 6,68 & 1,89 & 1,63 & 2,74 & 43,2 & 41,9 & 78,1 \\
\hline \multirow[t]{3}{*}{ Pousio/milho } & Dejetos $\left(\mathrm{m}^{3} \mathrm{ha}^{-1}\right)$ & 0 & 0,90 & 0,64 & 0,57 & 0,37 & 0,27 & 0,24 & 13,8 & 9,0 & 9,9 \\
\hline & & 40 & 0,90 & 1,17 & 1,88 & 0,39 & 0,50 & 0,79 & 13,8 & 17,0 & 30,8 \\
\hline & & 80 & 0,90 & 1,40 & 1,91 & 0,37 & 0,57 & 0,80 & 13,8 & 20,1 & 42,2 \\
\hline Pousio/milho & Uréia $\left(\mathrm{kg} \mathrm{ha}^{-1}\right)$ & 356 & 0,90 & 0,81 & 0,88 & 0,38 & 0,34 & 0,38 & 13,8 & 11,0 & 12,3 \\
\hline
\end{tabular}

(1) Aveia/milho: cultivo de aveia no outono/inverno e milho na primavera/verão; pousio/milho: desenvolvimento da vegetação espontânea da área no outono/inverno e milho na primavera/verão. 
tratamentos, foi efetuado o manejo da aveia na fase de florescimento pleno da cultura. Para isso, utilizouse um rolo-faca seguido da aplicação do herbicida glifosato (960 $\mathrm{g} \mathrm{ha}^{-1}$ de i.a.). Com esse manejo, no momento da aplicação dos tratamentos, os resíduos culturais da aveia estavam acamados sobre o solo. Para simplificação, os resíduos culturais dos dois sistemas de culturas, sobre os quais foram aplicados os tratamentos com dejetos em cada ano, foram denominados neste trabalho de aveia/milho e pousio/ milho. Os dejetos foram aplicados manualmente, com baldes, em cada parcela.

No sistema pousio/milho + N-uréia sem o uso de dejetos, o milho foi adubado com $70 \mathrm{~kg} \mathrm{ha}^{-1}$ de $\mathrm{P}_{2} \mathrm{O}_{5}$, $100 \mathrm{~kg} \mathrm{ha}^{-1} \mathrm{de} \mathrm{K}_{2} \mathrm{O}$ e $160 \mathrm{~kg} \mathrm{ha}^{-1}$ de N. A quantidade total de $\mathrm{P}$ e $\mathrm{K}$ foi aplicada na semeadura do milho. Quanto ao N, foram aplicados manualmente $30 \mathrm{~kg} \mathrm{ha}^{-1}$ de $\mathrm{N}$ logo após a semeadura do milho, na superfície do solo, junto ao sulco de semeadura. O restante do $\mathrm{N}$ foi dividido em duas aplicações em cobertura (65 $\mathrm{kg} \mathrm{ha}^{-1}$ de N), efetuadas manualmente a lanço, em toda a área das parcelas (Quadro 2). Quando necessário, foram realizadas irrigações por aspersão durante o ciclo da cultura do milho.

Os dejetos de suínos eram de animais criados em regime de confinamento total, sendo compostos pela mistura de fezes e urina dos animais e de outros materiais provenientes do processo criatório (água desperdiçada nos bebedouros, água de higienização, restos de alimentos, pêlos e poeira), além da água das chuvas, já que a esterqueira anaeróbia era descoberta.

A caracterização física e química dos dejetos foi realizada em quatro amostras coletadas no momento da sua aplicação no campo. Elas permaneceram cerca de $24 \mathrm{~h}$ em refrigerador $\left( \pm 4^{\circ} \mathrm{C}\right)$, até iniciarem-se as análises laboratoriais. Os teores de $\mathrm{N}$ total e de $\mathrm{N}$ amoniacal $\left(\mathrm{N}-\mathrm{NH}_{3}+\mathrm{N}-\mathrm{NH}_{4}{ }^{+}\right)$foram determinados sem a secagem prévia dos dejetos. $\mathrm{O} \mathrm{N}$ total foi determinado por meio da digestão úmida das amostras em ácido sulfúrico e mistura de digestão, e posterior destilação em semimicro Kjeldhal, enquanto o $\mathrm{N}$ amoniacal foi determinado por destilação em semimicro Kjeldhal após a adição de $\mathrm{MgO}$. Detalhes sobre o preparo das amostras para a determinação do $\mathrm{N}$ total e do $\mathrm{N}$ amoniacal dos dejetos líquidos estão descritos em Aita et al. (2007). A matéria seca foi determinada por meio da secagem em estufa a $65^{\circ} \mathrm{C}$ até peso constante. $\mathrm{O} \mathrm{pH}$ foi medido diretamente em potenciômetro em uma alíquota de aproximadamente $50 \mathrm{~mL}$ de dejetos enquanto o teor de $\mathrm{C}$ orgânico foi determinado no material seco a $65{ }^{\circ} \mathrm{C}$ e moído, conforme método descrito por Nelson \& Sommers (1982).

As quantidades de $\mathrm{N}$ total e $\mathrm{C}$ orgânico adicionadas pelos resíduos culturais da parte aérea da aveia e da vegetação espontânea no pousio invernal (Quadro 1) foram determinadas a partir da avaliação da quantidade de matéria seca (MS) produzida e dos teores desses dois elementos no tecido vegetal. Para tal, foram coletadas, aleatoriamente, duas subamostras de $0,49 \mathrm{~m}^{2}$ em cada parcela, que logo foram reunidas em uma amostra única. No momento da avaliação, a aveia encontrava-se no estádio de pleno florescimento. $\mathrm{O}$ material coletado foi submetido à secagem a $65^{\circ} \mathrm{C}$, em estufa com circulação de ar até peso constante, pesado, moído em um triturador de forragens, subamostrado e moído novamente em moinho equipado com peneira de 40 mesh. No material, seco e moído, foram determinados os teores de $\mathrm{N}$ total e C orgânico conforme métodos descritos em Bremner \& Mulvaney (1982) e Nelson \& Sommers (1982), respectivamente.

Quadro 2. Quantidade de nitrogênio aplicada com os dejetos de suínos e a uréia sobre os resíduos culturais de aveia/milho e pousio/milho nos três anos de experimentação

\begin{tabular}{|c|c|c|c|c|c|}
\hline \multirow{2}{*}{ Sistema $^{(1)}$} & \multirow{2}{*}{ Dose } & \multicolumn{2}{|c|}{ Dejeto de suíno } & \multicolumn{2}{|c|}{ Uréia } \\
\hline & & $\mathrm{N}$ total & $\mathrm{N}$ amoniacal & Dose & $\mathbf{N}$ \\
\hline & $\mathrm{m}^{3} \mathrm{ha}^{-1}$ & 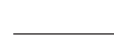 & $\mathrm{kg} \mathrm{ha}^{-1}$ & 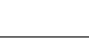 & 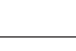 \\
\hline \multirow{4}{*}{ Aveia/milho e pousio/milho } & & & 1998/99 & & \\
\hline & 40 & 143,2 & 80,0 & - & - \\
\hline & & 286,4 & 160,0 & - & \\
\hline & & & $1999 / 00$ & & \\
\hline Aveia/milho e pousio/milho & 40 & 98,0 & 45,6 & & \\
\hline \multirow[t]{2}{*}{ Pousio/milho } & 80 & 196,0 & 91,2 & 356,0 & 160,0 \\
\hline & & & $2000 / 01$ & & \\
\hline Aveia/milho e pousio/milho & $\begin{array}{l}40 \\
80\end{array}$ & $\begin{array}{l}124,0 \\
248,0\end{array}$ & $\begin{array}{r}69,2 \\
138,4\end{array}$ & & \\
\hline Pousio/milho & & - & - & 356,0 & 160,0 \\
\hline
\end{tabular}


O calendário das principais atividades desenvolvidas no experimento durante os três anos agrícolas é mostrado no quadro 3.

A evolução das quantidades de $\mathrm{N}-\mathrm{NO}_{3}{ }^{-}$no solo foi acompanhada por meio da variação temporal dos teores de $\mathrm{N}_{-} \mathrm{NO}_{3}{ }^{-}$após a aplicação dos dejetos (Quadro 3), nas camadas $0-5 ; 5-15 ; 15-30$ e 30-60 cm do solo, o qual foi coletado por meio de um trado calador. No primeiro ano, as coletas foram efetuadas em quatro pontos distribuídos aleatoriamente dentro de cada subparcela. Em função da variabilidade nos teores de $\mathrm{N}-\mathrm{NO}_{3}{ }^{-}$nas camadas superficiais e nas primeiras amostragens, nos dois últimos anos o número de pontos amostrados em cada subparcela aumentou para oito nas três primeiras coletas. As subamostras foram misturadas constituindo-se uma amostra única, que foi acondicionada em sacos plásticos, levada para o laboratório e mantida em congelador a $-20^{\circ} \mathrm{C}$ até a execução das análises.

Por ocasião da análise, as amostras de solo foram descongeladas em temperatura ambiente e homogeneizadas manualmente. $\mathrm{O} \mathrm{N}_{-} \mathrm{NO}_{3}{ }^{-}$foi extraído do solo úmido, utilizando-se uma relação solo: solução extratora ( $\left.\mathrm{KCl} 1 \mathrm{~mol} \mathrm{~L}^{-1}\right)$ de 1:4. Após a eliminação do $\mathrm{N}$ amoniacal, pela adição de $0,2 \mathrm{~g}$ de $\mathrm{MgO}$ em uma alíquota de $20 \mathrm{~mL}$ do sobrenadante e destilação em destilador de arraste de vapor semimicro Kjeldahl, adicionou-se 0,2 g de liga de Devarda e fez-se nova destilação do mesmo extrato para a determinação de $\mathrm{N}-\mathrm{NO}_{2}{ }^{-}+\mathrm{N}_{-} \mathrm{NO}_{3}^{-}$(Keeney \& Nelson, 1982). Como, normalmente, os teores de $\mathrm{N}^{-\mathrm{NO}_{2}}{ }^{-}$no solo são extremamente baixos, considerou-se que todo o $\mathrm{N}$ mineral determinado na segunda destilação era representado pelo $\mathrm{NO}_{3}{ }^{-}$. Todos os resultados relativos às quantidades de $\mathrm{N}-\mathrm{NO}_{3}{ }^{-}$referem-se a solo seco a $105^{\circ} \mathrm{C}$ e considerando-se a concentração de $\mathrm{N}-\mathrm{NO}_{3}{ }^{-} \mathrm{e}$ a densidade do solo de cada camada determinada no início do experimento pelo método do anel volumétrico (Kiehl, 1979).

Os dados obtidos em cada ano foram interpretados pela análise da variância e as médias de tratamentos foram comparadas pelo teste de Tukey a $5 \%$. Esse procedimento foi adotado em razão de as quantidades de $\mathrm{N}$ aplicadas com os dejetos e as quantidades de resíduos culturais nos dois sistemas terem sido diferentes em cada ano. Em cada coleta realizada, a comparação das quantidades de $\mathrm{N}-\mathrm{NO}_{3}{ }^{-}$no perfil do solo de cada tratamento foi realizada separadamente para cada camada de solo analisada.

\section{RESULTADOS E DISCUSSÃO}

\section{Doses de dejetos e distribuição do $\mathrm{NO}_{3}{ }^{-}$no perfil do solo}

Nos três anos do experimento, a quantidade de $\mathrm{NO}_{3}{ }^{-}$ aumentou rapidamente nas camadas superficiais do solo (Figuras 1, 2 e 3). Esse rápido aparecimento de $\mathrm{NO}_{3}{ }^{-}$no solo ocorreu em conseqüência da elevada taxa de nitrificação do $\mathrm{N}$ amoniacal dos dejetos, conforme comprovado por Aita et al. (2007) em um experimento de campo em que o $\mathrm{N}$ amoniacal aplicado com os dejetos líquidos de suínos em plantio direto foi completamente nitrificado entre 15 e 20 dias após a aplicação dos dejetos. Além do rápido aparecimento de $\mathrm{NO}_{3}{ }^{-}$nas camadas mais superficiais no solo, os

Quadro 3. Calendário de atividades desenvolvidas nos três anos de experimentação e volume de água (precipitação pluvial + irrigação) em cada intervalo de coleta de solo

\begin{tabular}{|c|c|c|c|}
\hline Atividade & 1998/99 & $1999 / 00$ & $2000 / 01$ \\
\hline Manejo da aveia e da vegetação espontânea & $19 / 10 / 98$ & $11 / 10 / 99$ & $7 / 10 / 00$ \\
\hline Aplicação dos dejetos & $28 / 10 / 98$ & $22 / 10 / 99$ & $28 / 10 / 00$ \\
\hline Semeadura do milho & $30 / 10 / 98$ & 23/10/99 & $30 / 10 / 00$ \\
\hline \multicolumn{4}{|l|}{ Aplicação de uréia } \\
\hline Semeadura & - & $23 / 10 / 99$ & $30 / 10 / 00$ \\
\hline Cobertura 1 & - & 29/11/99 & $30 / 11 / 00$ \\
\hline Cobertura 2 & - & $17 / 12 / 99$ & $23 / 12 / 00$ \\
\hline \multicolumn{4}{|l|}{ Coletas de solo } \\
\hline Coleta 1 & $2 / 11 / 98(0,0)^{(1)}$ & $28 / 10 / 99(3,2)$ & $2 / 11 / 00(26,8)$ \\
\hline Coleta 2 & $7 / 11 / 98(14,1)$ & $8 / 11 / 99(77,1)$ & $8 / 11 / 00(49,4)$ \\
\hline Coleta 3 & $17 / 11 / 98(62,4)$ & $20 / 11 / 99(1,6)$ & $18 / 11 / 00(99,0)$ \\
\hline Coleta 4 & $27 / 11 / 98(43,0)$ & 7/12/99 $(99,4)$ & $3 / 12 / 00(62,4)$ \\
\hline Coleta 5 & $12 / 12 / 98(59,1)$ & 20/12/99 (99,3) & $28 / 12 / 00(140,6)$ \\
\hline Coleta 6 & $16 / 01 / 99(134,1)$ & $4 / 01 / 00(80,4)$ & $24 / 01 / 00(266,9)$ \\
\hline
\end{tabular}

(1) Números entre parênteses representam as quantidades de água em mm (precipitação pluvial + irrigação) em cada intervalo de coleta de solo, desde a aplicação dos dejetos. 
resultados (Figuras 1, 2 e 3 ) mostram que o $\mathrm{NO}_{3}^{-}$ aumentou com as quantidades de $\mathrm{N}$ total aplicadas com as doses de dejetos, as quais foram, em média, de 121 (40 $\left.\mathrm{m}^{3} \mathrm{ha}^{-1}\right)$ e de $243 \mathrm{~kg} \mathrm{ha}^{-1}$ de N (80 m ha-1).

Analisando a distribuição do $\mathrm{NO}_{3}^{-}$na camada 0-60 cm do solo, observa-se que o seu aparecimento nas camadas superficiais, logo após a aplicação dos dejetos, é acompanhado pela rápida transferência do $\mathrm{NO}_{3}{ }^{-}$para as camadas inferiores. Considerando, por exemplo, a dose de $80 \mathrm{~m}^{3} \mathrm{ha}^{-1}$, percebe-se que, aos 30 dias (Figura 1d), 29 dias (Figura 2c) e 36 dias (Figura 3d) após a aplicação dos dejetos, as quantidades de $\mathrm{N}_{-} \mathrm{NO}_{3}{ }^{-}$da camada mais profunda do solo (30$60 \mathrm{~cm}$ superaram aquelas da dose $0 \mathrm{~m}^{3} \mathrm{ha}^{-1} \mathrm{em} 9,21$ e $32 \mathrm{~kg} \mathrm{ha}^{-1}$ de $\mathrm{N}_{-} \mathrm{NO}_{3}^{-}$, respectivamente. Considerando que nesse período a demanda em $\mathrm{N}$ pelo milho ainda era pequena, é possível inferir que parte desse $\mathrm{N}_{-} \mathrm{NO}_{3}$, produzido pela oxidação do $\mathrm{N}$ amoniacal dos dejetos, pode ter sido lixiviado para além da profundidade de $60 \mathrm{~cm}$.
Mesmo com o aumento na capacidade de absorção de $\mathrm{N}$ pelo milho, observa-se que, aos 40 dias após o início do experimento no primeiro ano (Figura 1e), aos 59 dias no segundo ano (Figura 2e) e aos 61 dias do terceiro ano (Figura 3e), a quantidade média de $\mathrm{N}-\mathrm{NO}_{3}^{-}$da camada $30-60 \mathrm{~cm}$ do tratamento com $80 \mathrm{~m}^{3} \mathrm{ha}^{-1}$ superou a média do tratamento com $0 \mathrm{~m}^{3} \mathrm{ha}^{-1}$ em $15 \mathrm{~kg} \mathrm{ha}^{-1}$ de $\mathrm{N}-\mathrm{NO}_{3}^{-}$. Isto é um indicativo de que, em solos com características similares ao deste estudo, a dose de $80 \mathrm{~m}^{3} \mathrm{ha}^{-1} \mathrm{de}$ dejetos, cuja quantidade de $\mathrm{N}$ total aplicada no momento da semeadura do milho variou, nos três anos, de $196 \mathrm{~kg} \mathrm{ha}^{-1}$ a 286,4 $\mathrm{kg} \mathrm{ha}^{-1}$ (Quadro 2) pode representar um risco de perda de $\mathrm{N}$ por lixiviação, contribuindo para a diminuição do potencial fertilizante nitrogenado dos dejetos e para a contaminação da água do lençol freático. Além disso, o $\mathrm{N}_{-} \mathrm{NO}_{3}^{-}$poderá ser perdido por desnitrificação, poluindo a atmosfera pelo $\mathrm{N}_{2} \mathrm{O}$ produzido. É provável

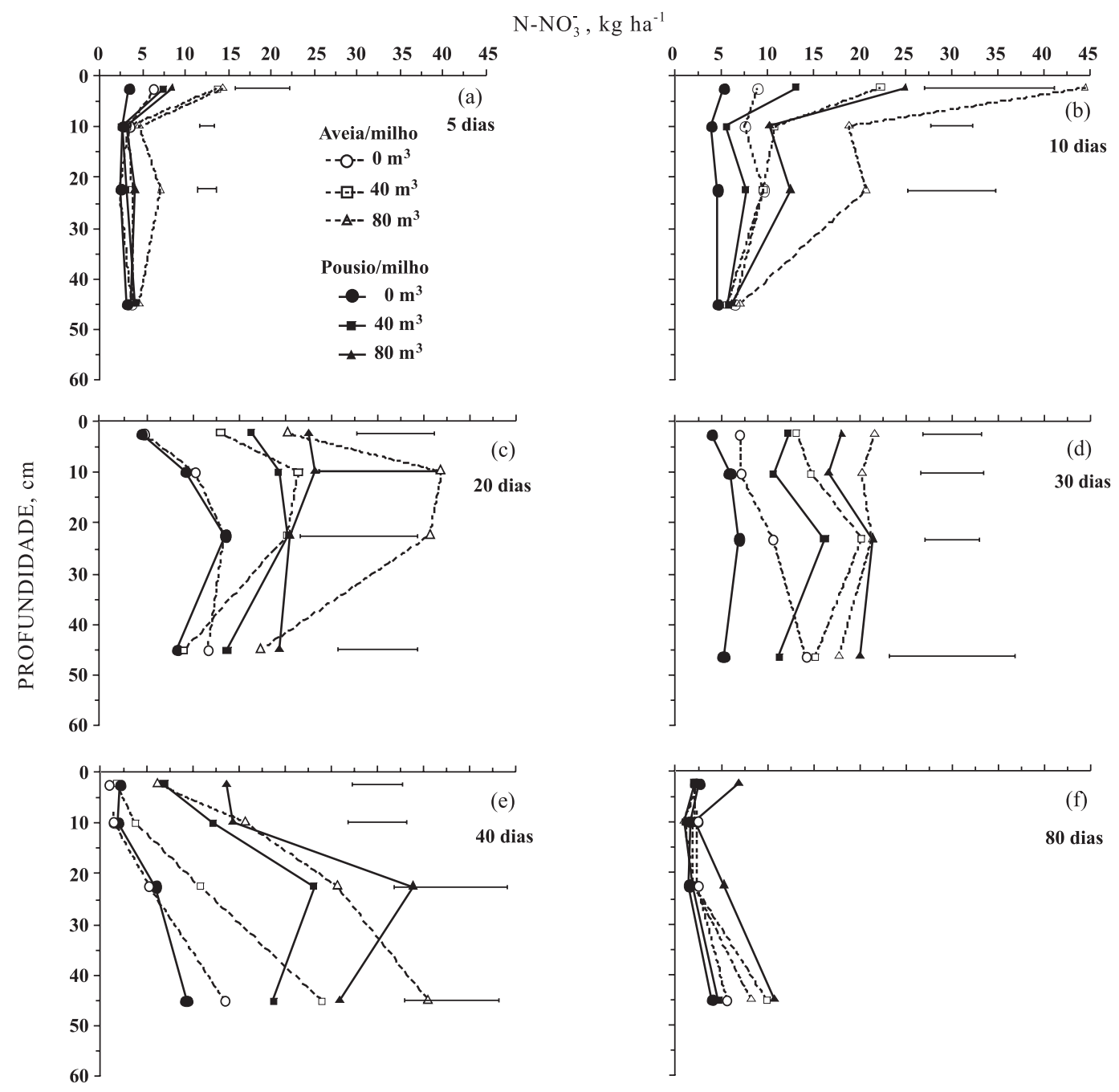

Figura 1. Quantidades de $\mathrm{N}-\mathrm{NO}_{3}{ }^{-}$na camada de 0-60 $\mathrm{cm}$ do solo durante o cultivo de milho, aos 5, 10, 20, 30, 40 e 80 dias após a aplicação dos dejetos $\left(0,40\right.$ e $\left.80 \mathrm{~m}^{3} \mathrm{ha}^{-1}\right)$, nos sistemas aveia/milho e pousio/milho nos três anos agrícolas (1998/99, 1999/00 e 2000/01). Nas profundidades em que existem barras horizontais, estas indicam diferença mínima significativa (Tukey a 5 \%). 

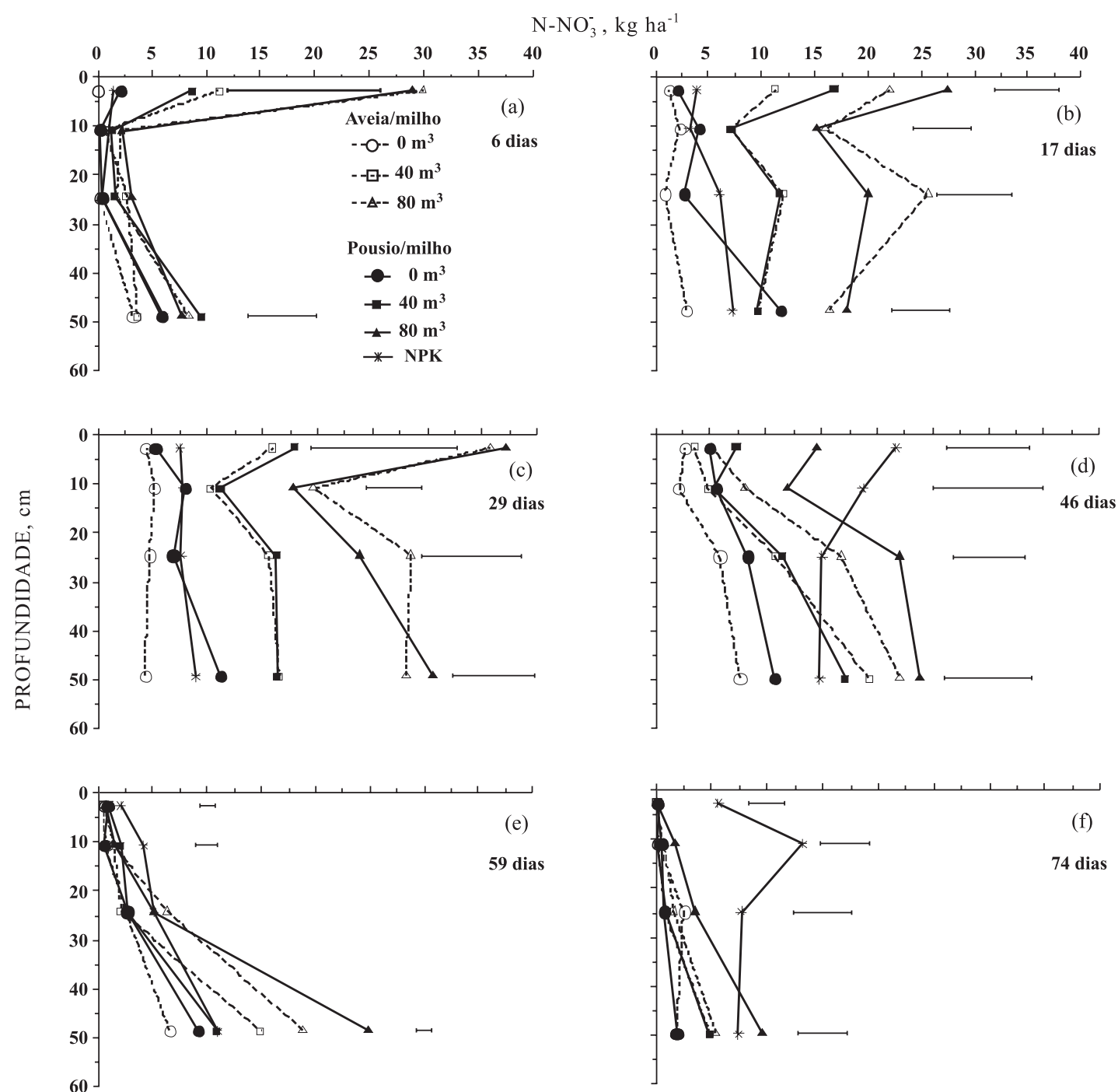

Figura 2. Quantidades de $\mathrm{N}_{-} \mathrm{NO}_{3}{ }^{-}$na camada de $0-60 \mathrm{~cm}$ do solo durante o cultivo de milho, aos 6, 17, 29, 46,

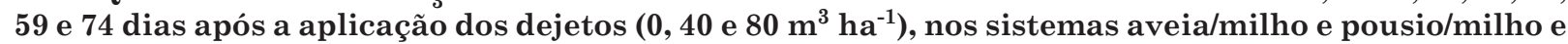
uréia no sistema pousio/milho nos três anos agrícolas (1998/99, 1999/00 e 2000/01). Nas profundidades em que existem barras horizontais, estas indicam diferença mínima significativa (Tukey a 5 \%).

que este processo seja favorecido na fase inicial de decomposição dos resíduos culturais, quando o $\mathrm{C}$ solúvel contido neles poderá migrar para regiões do solo com baixa disponibilidade de $\mathrm{O}_{2}$ (Giacomini et al., 2006). Anaerobiose e presença de $\mathrm{NO}_{3}{ }^{-}$e $\mathrm{C}$, são condições essenciais à atividade das bactérias responsáveis pela desnitrificação (Sylvia et al., 1998).

$\mathrm{Na}$ maioria dos trabalhos, as perdas de $\mathrm{N}$ por lixiviação após a aplicação de dejetos ou de $\mathrm{N}$ mineral têm sido avaliadas em lisímetros. Trabalhando em lisímetros com área de $1,5 \mathrm{~m}^{2}$ e $0,75 \mathrm{~m}$ de profundidade e com a cultura do milho, Daudén et al. (2004) constataram que, até a colheita do milho, foram perdidos $76 \mathrm{~kg} \mathrm{ha}^{-1}$ de $\mathrm{N}-\mathrm{NO}_{3}{ }^{-}$com a aplicação de $100 \mathrm{Mg} \mathrm{ha}^{-1}$ de dejetos líquidos de suínos (462 kg ha-1 de $\mathrm{N}-\mathrm{NH}_{4}{ }^{+}$), que foi a dose recomendada de nutrientes para os níveis de produtividade esperados para o milho. Quando a dose de dejetos foi duplicada (200 $\left.\mathrm{Mg} \mathrm{ha}^{-1}\right)$, a quantidade $\mathrm{N}-\mathrm{NO}_{3}{ }^{-}$perdida na água de drenagem aumentou para $313 \mathrm{~kg}$ ha-1 de $\mathrm{N}-\mathrm{NO}_{3}^{-}$. É importante considerar que essas quantidades de $\mathrm{N}-\mathrm{NH}_{4}{ }^{+}$aplicadas ao solo com os dejetos são aproximadamente três a seis vezes superiores à quantidade máxima de $\mathrm{N}-\mathrm{NH}_{4}{ }^{+}$ aplicada neste trabalho, que foi de $160 \mathrm{~kg} \mathrm{ha}^{-1}$ no primeiro ano e na dose de $80 \mathrm{~m}^{3} \mathrm{ha}^{-1}$ (Quadro 2). Com a aplicação de doses menores de dejetos líquidos de suínos (50,100, 150 e $200 \mathrm{~kg}^{-1}$ de $\mathrm{N}$ total, com $62,5 \%$ do $\mathrm{N}$ na forma amoniacal) e, portanto, mais próximas daquelas utilizadas neste trabalho, Bergström \& Kirchmann (2006) encontraram perdas de $\mathrm{N}_{-} \mathrm{NO}_{3}{ }^{-}$por lixiviação proporcionais às doses aplicadas, variando de 17 a $64 \mathrm{~kg} \mathrm{ha}^{-1} \mathrm{de} \mathrm{N}$. 

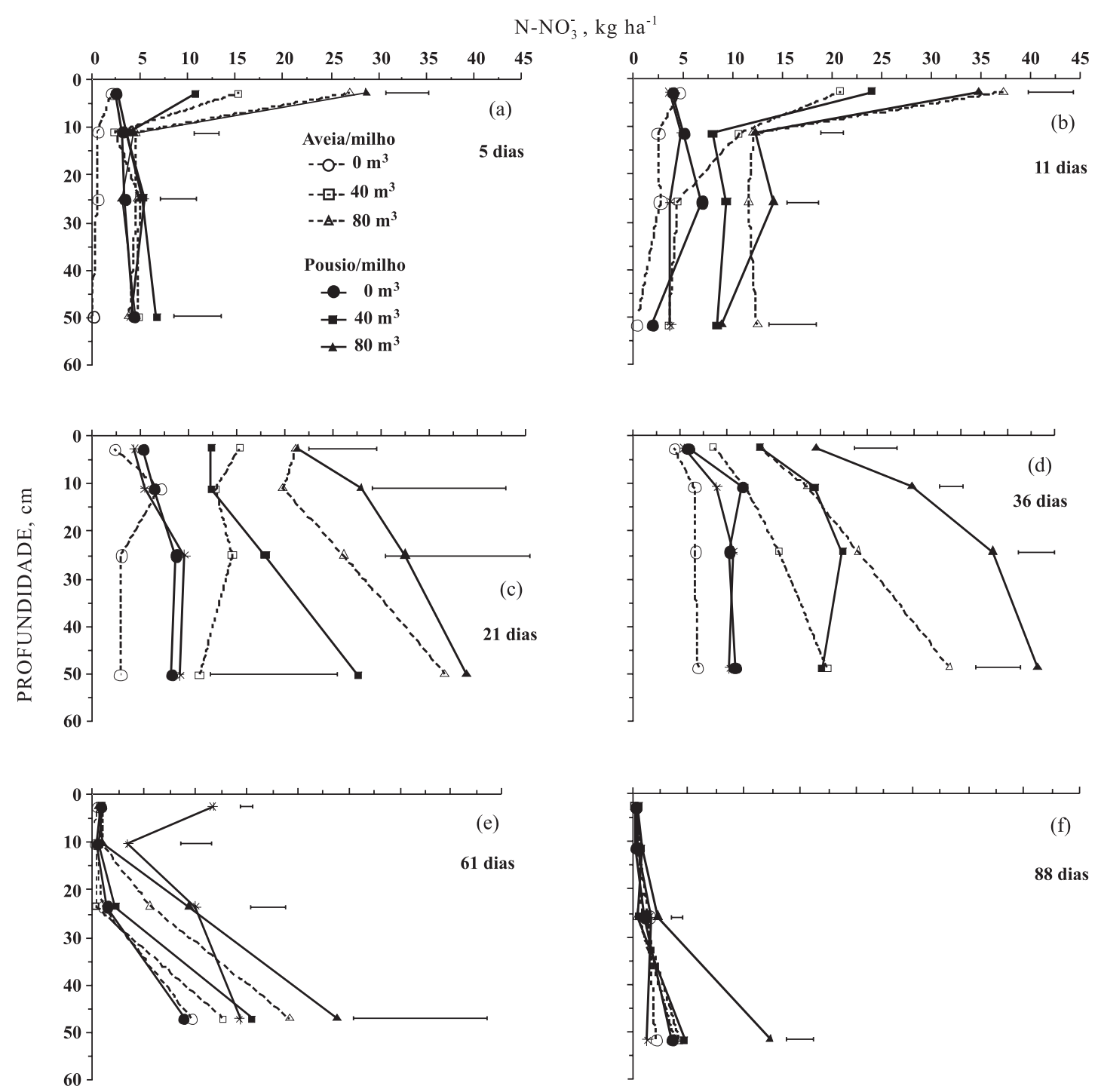

Figura 3. Quantidades de $\mathrm{N}-\mathrm{NO}_{3}{ }^{-}$na camada de 0-60 $\mathrm{cm}$ do solo durante o cultivo de milho, aos 5, 11, 21, 36, 61 e 88 dias após a aplicação dos dejetos $\left(0,40\right.$ e $\left.80 \mathrm{~m}^{3} \mathrm{ha}^{-1}\right)$, nos sistemas aveia/milho e pousio/milho e uréia no sistema pousio/milho nos três anos agrícolas (1998/99, 1999/00 e 2000/01). Nas profundidades em que existem barras horizontais, estas indicam diferença mínima significativa (Tukey a $5 \%$ ).

$\mathrm{Na}$ última avaliação realizada em cada ano (Figuras 1f, 2f e 3f), as quantidades de $\mathrm{N}-\mathrm{NO}_{3}{ }^{-}$nos tratamentos com aplicação de dejetos foram baixas, como conseqüência da absorção de $\mathrm{N}$ pelo milho e da provável transferência de $\mathrm{N}-\mathrm{NO}_{3}{ }^{-}$para profundidades maiores do que $60 \mathrm{~cm}$. Tais resultados coincidem com aqueles obtidos por Daudén et al. (2004) em que a quantidade de $\mathrm{N}-\mathrm{NO}_{3}{ }^{-}$na camada $0-75 \mathrm{~cm}$ de cinco tratamentos, incluindo adubação mineral (275 $\mathrm{kg} \mathrm{ha}^{-1}$ de $\mathrm{N}$ ) e doses crescentes de dejetos líquidos de suínos (231 a $924 \mathrm{~kg} \mathrm{ha}^{-1} \mathrm{de} \mathrm{N}$ ) foi de apenas $11 \mathrm{~kg} \mathrm{ha}^{-1} \mathrm{de}$ $\mathrm{N}-\mathrm{NO}_{3}{ }^{-}$na colheita do milho.

Embora os resultados obtidos (Figuras 1, 2 e 3 ) evidenciem a possibilidade de ter ocorrido perdas de $\mathrm{NO}_{3}{ }^{-}$por lixiviação, principalmente na dose de $80 \mathrm{~m}^{3}$ $\mathrm{ha}^{-1}$ de dejetos, a análise da variação temporal das concentrações de $\mathrm{N}-\mathrm{NO}_{3}{ }^{-}$, por meio da amostragem periódica de solo em diferentes camadas, conforme realizado neste trabalho, fornece apenas informações relativas à localização do $\mathrm{N}-\mathrm{NO}_{3}{ }^{-}$no perfil. Por meio deste método, não é possível calcular a quantidade de $\mathrm{N}-\mathrm{NO}_{3}{ }^{-}$lixiviada para além de $60 \mathrm{~cm}$. Para tal, seria necessária a determinação da concentração de $\mathrm{N}-\mathrm{NO}_{3}{ }^{-}$ na solução do solo, bem como do volume de água que drenou no espaço de tempo e na camada de solo considerados.

$\mathrm{O} \mathrm{NO}_{3}^{-}$que porventura tiver ultrapassado $60 \mathrm{~cm}$, somente irá atingir as águas do lençol freático, provocando sua contaminação, se a concentração de $\mathrm{NO}_{3}{ }^{-}$na solução do solo for suficientemente elevada e se a velocidade de deslocamento no $\mathrm{NO}_{3}{ }^{-}$no solo for maior do que a capacidade de sua absorção pelos 
microrganismos e de absorção pelas raízes do milho. Ao compararem o uso de dejetos de suínos e adubação mineral quanto à lixiviação de $\mathrm{NO}_{3}{ }^{-}$na cultura do milho, Daudén \& Quílez (2004) relataram que a absorção de água e de $\mathrm{NO}_{3}{ }^{-}$pelo milho foi insignificante, abaixo de $0,90 \mathrm{~m}$. Os autores consideraram que todo o $\mathrm{NO}_{3}{ }^{-}$encontrado abaixo desta profundidade representou um potencial poluidor da água. Para melhor estabelecer o potencial real dos dejetos de suínos em causar contaminação das águas subterrâneas com nitrato, seria interessante estender a coleta de solo para camadas além da zona de absorção do sistema radicular do milho, apesar das dificuldades metodológicas para tal. O uso de modelos matemáticos, baseados em medidas de $\mathrm{N}$ mineral no solo e de variáveis climáticas, durante a fase experimental, tem se mostrado uma estratégia promissora para a previsão das perdas de $\mathrm{NO}_{3}{ }^{-}$por lixiviação (Mary et al., 1999).

Os resultados desses estudos, realizados em lisímetros, e aquele deste trabalho, por meio de coleta de solo, mostram que a nitrificação do $\mathrm{N}$ amoniacal dos dejetos é rápida, ocorrendo o acúmulo de $\mathrm{NO}_{3}^{-}$no solo logo após a sua aplicação, quando o milho ainda não está absorvendo N. Outra constatação é a de que o $\mathrm{NO}_{3}{ }^{-}$é rapidamente transferido para camadas inferiores do perfil do solo, juntamente com a água das chuvas. Com isso, pode-se inferir que o potencial de contaminação tanto das águas superficiais como daquelas do lençol freático, via lixiviação de $\mathrm{NO}_{3}{ }^{-} \mathrm{e}$ também da atmosfera pelo $\mathrm{N}_{2} \mathrm{O}$ produzido durante a desnitrificação, aumenta com o uso de dejetos de suínos e que este risco é proporcional à quantidade de $\mathrm{N}$ aplicada. Uma maneira de diminuir estes problemas potenciais de contaminação do ambiente pelos dejetos líquidos de suínos poderia ser a aplicação parcelada em lugar de sua aplicação em dose única, antecedendo a semeadura. Embora esta estratégia não tenha sido avaliada neste trabalho, é provável que, com a aplicação de parte dos dejetos em cobertura, quando o milho apresentar um sistema radicular maior aumente a sincronia entre a produção de $\mathrm{NO}_{3}^{-}$e sua absorção pelo milho, diminuindo a quantidade de $\mathrm{NO}_{3}{ }^{-}$ susceptível a perdas.

\section{$\mathrm{NO}_{3}{ }^{-}$no perfil do solo com a aplicação dos dejetos e da uréia}

Comparando o tratamento com aplicação parcelada de uréia aos tratamentos com aplicação de dejetos em dose única de $80 \mathrm{~m}^{3} \mathrm{ha}^{-1}$, observa-se que, de maneira geral, após o primeiro mês, quando aumentou a demanda de $\mathrm{N}$ pelo milho, a uréia manteve maior, quantidade de $\mathrm{N}$ disponível nas camadas mais superficiais do solo, onde se concentra o sistema radicular da cultura. Além disso, no tratamento com uréia foi encontrada menor quantidade de $\mathrm{N}_{-} \mathrm{NO}_{3}{ }^{-}$nas camadas mais profundas (Figuras 2 e 3 ).

$\mathrm{Na}$ dose de $80 \mathrm{~m}^{3} \mathrm{ha}^{-1}$ de dejetos, foram aplicados $196 \mathrm{~kg} \mathrm{ha}^{-1}$ de $\mathrm{N}$ total no segundo ano e $248 \mathrm{~kg} \mathrm{ha}^{-1}$ de $\mathrm{N}$ total no terceiro ano, e 47 e $56 \%$ do N já estavam na forma amoniacal, respectivamente (Quadro 2). Assumindo um índice de mineralização de $35 \%$ do N orgânico dos dejetos de suínos, encontrado por Giacomini (2005), poderiam ser contabilizados mais $37 \mathrm{~kg} \mathrm{ha}^{-1}$ de $\mathrm{N}$ mineral no segundo ano e $38 \mathrm{~kg} \mathrm{ha}^{-1}$ no terceiro ano, totalizando $128 \mathrm{~kg} \mathrm{ha}^{-1}$ de $\mathrm{N}(91+$ $37 \mathrm{~kg} \mathrm{ha}^{-1}$ de N) e $176 \mathrm{~kg} \mathrm{ha}^{-1}$ de N $\left(138+38 \mathrm{~kg} \mathrm{ha}^{-1}\right.$ de N), respectivamente. Portanto, a quantidade média de $\mathrm{N}$ mineral proveniente da aplicação de $80 \mathrm{~m}^{3} \mathrm{ha}^{-1}$ de dejetos, potencialmente disponível ao milho, seria de $152,3 \mathrm{~kg} \mathrm{ha}^{-1}$ de $\mathrm{N}$, próxima da quantidade de $\mathrm{N}$ aplicada na forma de uréia (160 kg ha-1 de N).

Estes resultados indicam a provável falta de sincronia entre a liberação de $\mathrm{N}$ dos dejetos e a absorção de $\mathrm{N}$ pelo milho e evidenciam o maior potencial de perdas de $\mathrm{N}-\mathrm{NO}_{3}{ }^{-}$por lixiviação com a aplicação dos dejetos do que com $\mathrm{N}$ uréia, corroborando resultados de Bergström \& Kirchmann (2006), os quais trabalharam em um solo arenoso (83 a $93 \%$ de areia na camada de 0-100 cm), comparando a aplicação de doses equivalentes de $\mathrm{N}$ total (100 kg ha-1 de N) com dejetos de suínos e $\mathrm{N}$ mineral $\left(\mathrm{NH}_{4} \mathrm{NO}_{3}\right)$. Apesar de os dejetos apresentarem $37,5 \%$ do $\mathrm{N}$ na forma orgânica, os autores constataram que a perda de $\mathrm{N}$ por lixiviação durante os três anos de experimentação superou aquela do tratamento com $\mathrm{N}$ mineral em $17 \mathrm{~kg} \mathrm{ha}^{-1}$ de N (16\%). Tais resultados, aliados aos deste trabalho, reforçam a hipótese de que o parcelamento dos dejetos, conforme foi feito com a uréia, pode diminuir as perdas de $\mathrm{N}_{-} \mathrm{NO}_{3}{ }^{-}$por lixiviação, melhorando seu potencial fertilizante e diminuindo seu potencial poluente.

\section{Efeito dos resíduos culturais na quantidade e distribuição de $\mathrm{NO}_{3}^{-}$no perfil do solo}

Uma das hipóteses deste trabalho era a de que a aplicação dos dejetos de suínos, contendo de 46,5 a $55,9 \%$ do $\mathrm{N}$ total na forma amoniacal (Quadro 2), diretamente sobre os resíduos culturais de aveia, cuja adição de $\mathrm{C}$ nos três anos variou de 1,29 a $2,74 \mathrm{Mg}^{-1}$ (Quadro 1), estimularia a imobilização, pela população microbiana, de parte do $\mathrm{NO}_{3}{ }^{-}$resultante da oxidação do $\mathrm{N}$ amoniacal dos dejetos. Com isso, a aplicação dos dejetos sobre os resíduos culturais de aveia deveria resultar em menores quantidades de $\mathrm{NO}_{3}{ }^{-}$no solo, em relação à aplicação de dejetos sobre os resíduos culturais da vegetação espontânea. Todavia, observase, através dos perfis de $\mathrm{N}-\mathrm{NO}_{3}{ }^{-}$do primeiro ano (Figura 1), que com a dose de $40 \mathrm{~m}^{3} \mathrm{ha}^{-1}$ de dejetos, praticamente não houve diferenças significativas na aplicação dos dejetos sobre os resíduos culturais da aveia ou da vegetação espontânea. Já na dose de $80 \mathrm{~m}^{3} \mathrm{ha}^{-1}$ de dejetos, contrariamente ao esperado, quando as quantidades de $\mathrm{N}-\mathrm{NO}_{3}{ }^{-}$diferiram-se, as diferenças ocorreram em favor do tratamento com aplicação dos dejetos sobre os resíduos culturais da aveia-preta.

No segundo ano (Figura 2), os perfis de $\mathrm{N}-\mathrm{NO}_{3}{ }^{-}$ com a dose de $40 \mathrm{~m}^{3} \mathrm{ha}^{-1}$ foram novamente semelhantes 
entre os tratamentos com resíduos culturais da vegetação espontânea e da aveia, e com a dose de $80 \mathrm{~m}^{3}$ ha $^{-1}$ observou-se que, a partir da amostragem realizada aos 46 dias (Figura 2d), houve tendência do tratamento com resíduos culturais de aveia apresentar menores quantidade de $\mathrm{N}-\mathrm{NO}_{3}{ }^{-}$, principalmente na camada mais profunda $(30-60 \mathrm{~cm})$.

No terceiro ano (Figura 3), observa-se que, tanto com a dose de $40 \mathrm{~m}^{3} \mathrm{ha}^{-1}$ quanto, principalmente com a de $80 \mathrm{~m}^{3} \mathrm{ha}^{-1}$, houve diferenças significativas nas quantidades de $\mathrm{N}-\mathrm{NO}_{3}{ }^{-}$em algumas amostragens e em algumas camadas de solo, sempre com maiores valores no tratamento com resíduos culturais da vegetação espontânea. Na amostragem realizada aos 36 dias (Figura 3d) e com a dose de $80 \mathrm{~m}^{3} \mathrm{ha}^{-1}$, a diferença foi significativa em todas as camadas avaliadas, e a soma das quantidades de $\mathrm{N}-\mathrm{NO}_{3}{ }^{-}$até a profundidade de $60 \mathrm{~cm}$ do tratamento com resíduos culturais da vegetação espontânea foi $41 \mathrm{~kg} \mathrm{ha}^{-1}$ maior do que no tratamento com aveia. É provável que este efeito dos resíduos culturais sobre a diminuição das quantidades de $\mathrm{N}-\mathrm{NO}_{3}{ }^{-}$do solo tenha sido mais significativo no terceiro ano dado o acúmulo gradativo de resíduos culturais e de $\mathrm{C}$ (parte aérea e raízes) no solo com o cultivo anual de aveia e milho na mesma área, o que deve aumentar o potencial de imobilização de N-NO ${ }_{3}^{-}$pela biomassa microbiana. Todavia, é importante considerar também o fato de que aplicações repetidas de dejetos de suínos na mesma área poderão contribuir para o aumento gradativo do estoque de $\mathrm{N}$ orgânico no solo e, conseqüentemente, na produção de $\mathrm{N}-\mathrm{NO}_{3}{ }^{-}$por meio do processo microbiano de mineralização. Com a dose de $80 \mathrm{~m}^{3} \mathrm{ha}^{-1}$ de dejetos, a quantidade de $\mathrm{N}$ total aplicada nos três anos foi de $730 \mathrm{~kg} \mathrm{ha}^{-1}$, dos quais $345 \mathrm{~kg} \mathrm{ha}^{-1}$ faziam parte de compostos nitrogenados orgânicos (Quadro 2). Por isso, a importância na realização de experimentos por médio a longo prazos, repetindo-se a aplicação dos dejetos na mesma área, conforme é feito em inúmeras propriedades rurais.

Este conjunto de resultados relativos aos perfis de $\mathrm{NO}_{3}{ }^{-}$, desde a aplicação dos dejetos até o florescimento pleno do milho (Figuras 1, 2 e 3), sugere que o potencial de imobilização de $\mathrm{N}$ por parte dos resíduos culturais da aveia, quando estes permanecem na superfície do solo, é menor do que aquele encontrado em outros estudos (Darwis, 1993; Chantigny et al., 2001), tendo pouco efeito sobre a diminuição da lixiviação de $\mathrm{NO}_{3}{ }^{-}$. Provavelmente, o contato limitado dos resíduos culturais com o solo no plantio direto, dificultando o acesso dos microrganismos à fonte de $\mathrm{C}$, aliado à ocorrência de chuvas após a aplicação dos dejetos, carregando o $\mathrm{N}$ amoniacal dos dejetos para além da zona ativa de decomposição, sejam os principais fatores determinantes deste resultado. Isto evidencia que não basta a presença de $\mathrm{C}$ e $\mathrm{N}$ mineral no solo para que ocorra o processo microbiano de imobilização líquida de $\mathrm{N}$, pelo menos em nível que possa ser detectado analiticamente por meio da determinação dos teores de $\mathrm{N}$ mineral. Aparentemente, há necessidade de otimizar o contato entre a fonte de $\mathrm{C}$ e a população microbiana, para que a magnitude do processo de imobilização de $\mathrm{N}$ possa alterar significativamente a disponibilidade de $\mathrm{N}$ no solo. Portanto, o objetivo de limitar as perdas de $\mathrm{NO}_{3}{ }^{-}$por lixiviação via imobilização microbiana dificilmente será alcançado no sistema plantio direto, onde os resíduos culturais permanecem na superfície do solo.

A relação $\mathrm{C} / \mathrm{N}$ dos resíduos culturais também deve afetar a magnitude da imobilização do $\mathrm{N}$ e por conseqüência, as perdas de $\mathrm{NO}_{3}{ }^{-}$por lixiviação. Será que a $\mathrm{C} / \mathrm{N}$ da aveia, cujo valor nunca ultrapassou a 42 (Quadro 1), foi suficientemente elevada a ponto de aumentar a demanda microbiana por uma fonte externa de $\mathrm{N}$ ? O efeito do contato entre os resíduos culturais e o solo e da relação $\mathrm{C} / \mathrm{N}$ sobre a imobilização microbiana de $\mathrm{N}$ são alguns dos principais aspectos que necessitam ser mais avaliados pela pesquisa, sobretudo com o uso de dejetos líquidos de suínos em plantio direto. Nesses estudos, é importante avaliar simultaneamente as biotransformações do $\mathrm{C}$ e do $\mathrm{N}$, haja vista a relação estreita entre a dinâmica desses dois elementos durante a decomposição de materiais orgânicos no solo, conforme enfatizado por Chantigny et al. (2001). O uso de dejetos cuja fração amoniacal tenha sido uniformemente marcada com ${ }^{15} \mathrm{~N}$, conforme feito por Morvan et al. (1997), também poderá contribuir para acompanhar o destino desta fração de $\mathrm{N}$ no sistema solo/planta/atmosfera.

\section{CONCLUSÕES}

1. A aplicação de dejetos de suínos sobre a palha de aveia como estratégia para estimular a imobilização microbiana de $\mathrm{N}$, reduzindo o potencial de lixiviação de $\mathrm{NO}_{3}{ }^{-}$no solo, mostrou-se ineficiente.

2. As quantidades de $\mathrm{N}-\mathrm{NO}_{3}{ }^{-}$e a sua percolação no solo aumentaram rapidamente após a aplicação dos dejetos, principalmente na dose de $80 \mathrm{~m}^{3} \mathrm{ha}^{-1}$.

\section{LITERATURA CITADA}

AITA, C.; GIACOMINI, S.J. \& HÜBNER, A.P. Nitrificação do nitrogênio amoniacal de dejetos líquidos de suínos em solo sob sistema de plantio direto. Pesq. Agropec. Bras., 42:95-102, 2007

BERGSTRÖM, L. \& KIRCHMANN, H. Leaching and crop uptake of nitrogen and phosphorus from pig slurry as affected by different application rates. J. Environ. Qual., 35:1803-1811, 2006.

BREMNER, J.M. \& MULVANEY, C.S. Nitrogen-Total. In PAGE, A.L.; MILLER, R.H. \& KEENEY, D.R., eds. Methods of soil analysis: Chemical and microbiological properties. Part 2. Madison, Soil Science Society of America, 1982. p.539-579. 
CHANTIGNY, M.H.; ANGERS, D.A.; MORVAN, T. \& POMAR, C. Dynamics of pig slurry nitrogen in soil and plant as determined with ${ }^{15}$ N. Soil Sci. Soc. Am. J., 68:637-643, 2004.

CHANTIGNY, M.H.; ROCHETTE, P. \& ANGERS, D.A. Shortterm $\mathrm{C}$ and $\mathrm{N}$ dynamics in a soil amended with pig slurry and barley straw: A field experiment. Can. J. Soil Sci., 81:131-137, 2001

DARWIS, D. Effet des modalités de gestion de la paille de blé sur l'évolution du carbone et l'azote au cours de sa décompositiom dans le sol. Paris, Université Paris 6, Sciences de la Terre, 1993. 196p. (Tese de Doutorado)

DAUDÉN, A. \& QUÍLEZ, D. Pig slurry versus mineral fertilization on corn yield and nitrate leaching in a Mediterranean irrigated environment. Eur. J. Agron., 21:7-19, 2004.

DAUDÉN, A.; QUÍLEZ, D. \& VERA, M.V. Pig slurry application and irrigation effects on nitrate leaching in mediterranean soil lysimeters. J. Environ. Qual., 33:2290-2295, 2004.

EMPRESA BRASILEIRA DE PESQUISA AGROPECUÁRIA EMBRAPA. Centro Nacional de Pesquisa de Solos. Sistema brasileiro de classificação de solos. Brasília, 1999. $412 \mathrm{p}$.

FLOWERS, T.H. \& O'CALLAGHAN, O.R. Nitrification in soils incubated with pig slurry or ammonium sulphate. Soil Biol. Biochem., 13:337-342, 1983.

GIACOMINI, S.J. Avaliação e modelização da dinâmica de carbono e nitrogênio com o uso de dejetos de suínos. Santa Maria, Universidade Federal de Santa Maria, 2005. 240p. (Tese de Doutorado)
GIACOMINI, S.J.; JANTALIA, C.P.; AITA, C.; URQUIAGA, S.A. \& ALVES, B.J.R. Emissão de óxido nitroso com a aplicação de dejetos líquidos de suínos em solo sob plantio direto. Pesq. Agropec. Bras., 41:1653-1661, 2006.

KEENEY, D.R. \& NELSON, D.W. Nitrogen-Inorganic forms. In: PAGE, A.L.; MILLER, R.H. \& KEENEY, D.R., eds. Methods of soil analysis: Chemical and microbiological properties. Part 2. Madison, Soil Science Society of America, 1982. p.539-579.

KIEHL, J. Manual de edafologia: Relações solo-planta. São Paulo, Agronômica Ceres, 1979. 262p.

MARY, B.; BEAUDOIN, N.; JUSTES, E. \& MACHET, J.M. Calculation of nitrogen mineralization and leaching in fallow soil using a simple dynamic model. Eur. J. Soil Sci., 50:549-566, 1999.

MORVAN, T.; LETERME, P.; ARSENE; G.G. \& MARY, B. Nitrogen transformations after the spreading of pig slurry on bare soil and ryegrass using ${ }^{15} \mathrm{~N}$-labelled ammonium. Eur. J. Agron., 7:181-188, 1997.

NELSON, D.W. \& SOMMERS, L.E. Total carbon, organic carbon and organic matter. In: PAGE, A.L.; MILLER, R.H. \& KEENEY, D.R., eds. Methods of soil analysis: Chemical and microbiological properties. Part 2. Madison, Soil Science Society of America, 1982. p.539-579.

SOMMER, S.G. \& HUSTED, S. The chemical buffer system in raw and digested animal slurry. J. Agric. Sci., 124:45-53, 1995.

SYLVIA, D.M.; FUHRMANN, J.J.; HARTEL, P.G. \& ZUBERER, D.A. Principles and applications of soil microbiology. New Jersey, Prentice Hall, 1998. 550p. 